\title{
Campaign Spending and Incumbency: An Alternative Simultaneous Equations Approach
}

\author{
Robert S. Erikson \\ University of Houston \\ Thomas R. Palfrey \\ California Institute of Technology
}

This paper estimates the effects of incumbent spending and challenger spending in U.S. House elections in the 1970s and 1980s. The paper employs FIML simultaneous equations analysis involving instrumental variables as vote predictors, and zero-covariance restrictions for the vote-spending disturbances. This procedure allows the estimation of spending effects given plausible assumptions about the effects of unobserved causes of the vote on candidate spending. The results are that incumbent spending matters even with only modest amounts of simultaneity. Evidence is presented to suggest that the effectiveness of new incumbent spending declines with seniority but accumulates to the incumbent's long-term advantage.

\section{Introduction}

Common wisdom is that money is a major contributor to the electoral success of incumbents in U.S. House elections. The argument goes roughly like this. Candidates must spend lavishly to win over congressional voters. Hustling the necessary cash from contributors in return for access, incumbents generally are able to outspend any challenger who might threaten them. Thus, they almost always win reelection. Aware that incumbents are protected by their cash advantage, potential opponents rarely offer more than token challenges. The process perpetuates a system whereby most congressional races are not seriously contested.

Although the foregoing argument has a familiar resonance, it is by no means the conclusion one reaches from reading most empirical studies by political science journals. As Jacobson first showed with his pioneering work (1978, 1980, 1985), OLS regressions of the district vote present the odd result that while challenger spending matters, the coefficient for incumbent spending is always near zero and sometimes even with the wrong sign, due to simultaneity problems.

We gratefully acknowledge the support of NSF through grants SES-9224787 and SES-9223868. We thank Darren Davis for his research assistance. 
Subsequent efforts to correct for this using instrumental variables (Bartels 1992; Green and Krasno 1988) have not been entirely satisfactory. The most generous instrumental variable estimates of incumbent spending effects are considerably smaller than those for challenger spending, and arguably biased upward to boot (Abramowitz 1991; Jacobson 1990). If the relative spending advantage goes to challengers rather than incumbents, then incumbents' advantage from free resources must be considerably greater than recognized. According to the incumbency literature (e.g., Alford and Brady 1993; Erikson 1972; Gelman and King 1990), incumbents gain five or more percentage points (on average) just for being incumbents. If incumbents must overcome a disadvantage in terms of spending effects, then the incumbency advantage from other sources becomes even more impressive, and mysterious in its origins, than previously thought.

The real question then is, How much (if any) of the incumbency advantage is attributable to spending differentials? To answer this, we look at the net spending advantage for the incumbent or challenger in terms of the following identity:

$$
\text { Net spending advantage }=\beta_{I}(I E)+\beta_{C}(C E)
$$

where the net spending advantage is measured in units of incumbent vote share, $\beta_{I}$ and $\beta_{C}$ represent coefficients for incumbent vote increments gained per unit of spending, and $I E$ and $C E$ represent expenditure units (such as dollars spent).

The net advantage depends on both the effect coefficients and the gross expenditures, so that a lesser efficiency at converting dollars to votes can be offset by outspending one's opponent. For instance, the net spending advantage would be zero when:

$$
\frac{I E}{C E}=\frac{\beta_{C}}{\beta_{I}}
$$

For example, suppose the spending effects themselves were actually equal for incumbents and challengers $\left(\beta_{I}=-\beta_{C}\right)$. Then, incumbents would enjoy a spending advantage from the fact that they outspend their challengers. Consider even the possibility that incumbents might spend more effectively than their challengers $\left(\beta_{I}>-\beta_{C}\right)$. Incumbents would gain both from spending more and spending more effectively. The result would be an incumbent spending advantage sufficiently large to account for much if not all of the overall advantage of incumbency.

Thus we raise the possibility that the popular (as opposed to political science) view of the incumbency advantage is correct in at least its more important respects. With parity of incumbent and challenger spending coefficients, the net spending advantage goes to the higher-spending incumbents. If incumbents spend even slightly more effectively than their often amateurish challenger opponents, money would be a major source of the overall incumbency advantage. 
Of course, this sort of speculation faces one key obstacle: the pervasive finding in the literature on spending effects that $\beta_{I}$ is dwarfed by $\beta_{C}$.

The present paper reexamines the statistical evidence regarding the relative effects of incumbent and challenger spending on the vote. We find that incumbent spending is of considerable importance in House elections and a major source of the incumbency advantage. The reason why such evidence has been elusive in earlier studies, we argue, is that the statistical strength of the reverse effect of close elections on spending has been seriously underestimated. Our paper offers four innovative features.

"UNCORRELATED ERRORS" METHODOLOGY. Statistically, we present a new way to identify the vote model by making assumptions about the covariances of the error terms. This permits estimation of spending effects in the presence of simultaneity that arises because the level of spending depends on candidates' expectations about how close the election will be. We then extend this model to estimate the severity of the simultaneity problem.

CONDITIONING SPENDING EFFECTS ON SENIORITY. We separately analyze spending effects for different seniority levels, and find large differences, especially between freshmen and veterans. Spending effects are of special interest for freshman members of Congress, as past studies have shown it is in the first reelection that House members gain the lion's share of their incumbency advantage. Our results shed some light on why this is so. We estimate the buildup of an incumbency advantage using a cumulative model of spending effects, and show that this closely tracks the actual time profile of the incumbency advantage.

TWO-DECADE TIME FRAME. We analyze congressional district election results over two decades, from 1972 to 1990 , pooling this data into one massive dataset.

DISTRICT-LEVEL "PAR." As an innovation, using data from open seat elections we estimate district-level partisanship from district presidential voting. Par is an incumbency-neutral and spending-neutral estimate of the combination of the normal vote and short-term forces (or year effects).

\section{Open Seats: Spending Effects and the Measurement of Par}

The analysis begins with an investigation of spending effects for open seatsthose with no incumbent running. We start there for two reasons. First, since effects of spending for open seats should be about equal for both Republican and Democratic candidates (neither is the incumbent), open seats should provide unbiased estimates of the potential effect parameters for challengers and incumbents in incumbent races. Second, we exploit our open seat analysis to 
obtain estimates of a baseline we call "Par." Par is the expected vote independent of candidate considerations-given district partisanship ("normal vote"), the election year's partisan trend ("national short term forces"), no incumbent candidate, and equal (canceling) Republican and Democratic spending effects.

As a reflector of district partisanship, the district-level presidential vote is the major component of Par. For the 1970s, the one presidential vote measure that predicts the congressional vote well, regardless of election year, is the CarterFord 1976 vote. For the 1980s, the Dukakis-Bush 1988 vote serves this purpose. ${ }^{1}$

Par represents a particular baseline: the expected congressional vote, given the district's relevant presidential voting history and the election-year partisan trend, for an open seat where Democratic and Republican spending levels are balanced. Table 1 shows how this was done. For open seats of the 1970s, the first column shows a regression of the percent Democratic vote on the Carter 1976 percentage, four election-year dummies, and the net difference between the $\log$ of Democratic spending and the log of Republican spending. To adjust for regional differences, a "south" dummy and a "south" $\times$ presidential vote interaction term were also added. As shown in column 2, this procedure was replicated for the 1980 s using the 1988 presidential vote as the district partisanship measure. The third column shows the pooled estimates, using a common estimate of spending effects. The boxed portion of column 3 is the measure of Par. Par is the open seat equation prediction, with the estimated effect of spending subtracted from it. ${ }^{2}$

Note that the spending effect is modeled as a linear effect of logged spending on the two-party vote division. This specification allows the marginal effect of the next dollar to diminish with the amount already spent. By the usual criteria of best-fitting $R$-squared, lower standard error of estimate, etc., logged spending vastly outperforms raw spending as a vote predictor. To maintain a comparable monetary scale for different election years, we measure spending in terms of constant (1978) dollars. To avoid problems with several cases of "no spending" (the $\log$ of zero is minus infinity), we adopt Green and Krasno's (1988) convention, measuring the spending variable as the log of the candidate's spending plus $\$ 5,000$ (in 1978 dollars).

\footnotetext{
${ }^{\mathrm{I}}$ The presidential vote for other election years $(1972,1980$ for the $1970 \mathrm{~s} ; 1984$ for the $1980 \mathrm{~s})$ does not add significantly to the prediction of the open seat vote within the decade. For the 1980s, the 1984 presidential vote could be substituted for the 1988 vote. The two vote measures correlate at +.97 .

${ }^{2}$ Some side evidence suggests that Par is a very accurate reflection of cross-district differences in partisanship. For example, with Par in the equation, the lagged ( $T-2$ years) congressional vote does not even make a statistically significant contribution to the open seat vote. That is, if one knows the presidential vote (for 1976 for the 1970s; 1988 for the 1980s) plus the election year and region, the district's congressional election history does not help to predict the open seat congressional vote. Evidently, most relevant information about district partisanship is contained in Par. If Par were a leaky measure of district partisanship, partisanship would be reflected by the district's congressional election history.
} 
TABLE 1

Predicting the Open Seat Vote, 1972-1990

\begin{tabular}{|c|c|c|c|}
\hline Open Variance $=$ Percent Dem & $1972-80$ & $1982-90$ & $1972-90$ \\
\hline Log Democrat spending & 4.33 & 5.08 & 4.70 \\
\hline - log Republican spending & $(8.32)$ & $(9.89)$ & $(12.80)$ \\
\hline Democrat presidential vote, & 0.74 & 0.47 & 0.71 \\
\hline 1976 or 1988 & $(11.58)$ & $(6.83)$ & $(12.54)$ \\
\hline \multirow[t]{2}{*}{ South dummy } & 15.90 & 6.38 & 15.52 \\
\hline & $(2.44)$ & $(1.08)$ & $(2.42)$ \\
\hline \multirow[t]{2}{*}{ South $\times$ Democrat presidential vote } & -0.33 & -0.06 & -0.32 \\
\hline & $(-2.76)$ & $(-0.43)$ & $(-2.73)$ \\
\hline \multirow[t]{2}{*}{ South $\times$ Decade 1980 s } & & & -8.81 \\
\hline & & & $(-1.00)$ \\
\hline Decade $1980 \mathrm{~s} \times$ & & & -0.21 \\
\hline Democrat Presidential Vote & & & $(-2.86)$ \\
\hline South $\times$ Decade $1980 \mathrm{~s}$ & & & 0.26 \\
\hline$\times$ Democrat Presidential Vote & & & $(1.42)$ \\
\hline \multicolumn{4}{|l|}{ Year } \\
\hline \multirow[t]{2}{*}{1974} & 6.23 & & 6.14 \\
\hline & $(4.74)$ & & $(4.47)$ \\
\hline \multirow[t]{2}{*}{1976} & 6.33 & & 6.21 \\
\hline & $(4.54)$ & & $(4.52)$ \\
\hline \multirow[t]{2}{*}{1978} & 1.65 & & 1.68 \\
\hline & $(1.21)$ & & $(1.24)$ \\
\hline \multirow[t]{2}{*}{1980} & 0.75 & & 0.88 \\
\hline & $(0.51)$ & & $(0.61)$ \\
\hline \multirow[t]{2}{*}{1982} & & & 16.03 \\
\hline & & & $(4.21)$ \\
\hline \multirow[t]{2}{*}{1984} & & -4.73 & 11.38 \\
\hline & & $(-2.82)$ & $(2.99)$ \\
\hline \multirow[t]{2}{*}{1986} & & -2.29 & 11.73 \\
\hline & & $(-1.54)$ & (3.69) \\
\hline \multirow[t]{2}{*}{1988} & & -4.47 & 11.68 \\
\hline & & $(-2.67)$ & $(3.04)$ \\
\hline \multirow[t]{2}{*}{1990} & & -1.04 & 15.18 \\
\hline & & $(-0.63)$ & $(4.09)$ \\
\hline \multirow[t]{2}{*}{ Constant } & 12.45 & 31.55 & 13.82 \\
\hline & $(3.82)$ & $(8.88)$ & $(4.72)$ \\
\hline Adjusted $R^{2}$ & .739 & .749 & .739 \\
\hline Standard error of est. & 6.76 & 6.55 & 6.68 \\
\hline Number of Cases & $(241)$ & $(163)$ & $(404)$ \\
\hline
\end{tabular}

Note: Log of Democrat Spending, Log of Republican Spending = Natural Log of Candidate Spending plus $\$ 5,000$, all in constant (1978) dollars.

$t$-values in parentheses

$\mathrm{Par}=$ Boxed Component 
Not to be lost in the shuffle of our discussion of Par are the estimated effects of spending by open seat candidates. Spending coefficients are quite significant statistically for both Republican and Democratic candidates. For the measurement of Par, we simply utilize the net difference in logged spending between the two parties.

\section{The Uncorrelated Errors Solution}

In this section, we present our methodology, utilizing a zero-covariance restriction for the disturbance terms or, simply, "uncorrelated errors." The zero covariance refers to the assumed lack of correlation across selected residuals in the structural equations. This permits identification of the three-equation system presented below.

The three estimated equations, omitting the constant terms, are:

$$
\begin{gathered}
I E=\beta_{11}(I V)+\beta_{12}(T)+\epsilon_{1} \\
C E=\beta_{21}(I V)+\beta_{22}(T)+\epsilon_{2} \\
I V=\beta_{31}(I E)+\beta_{32}(C E)+\beta_{33}(\text { Par })+\beta_{34}(L N V)+\beta_{35}(T)+\epsilon_{3}
\end{gathered}
$$

where $\operatorname{cov}\left(\epsilon_{1}, \epsilon_{3}\right)=\operatorname{cov}\left(\epsilon_{2}, \epsilon_{3}\right)=0$ and:

$I V=$ incumbent's percent of two-part vote

$I E=\log$ of Incumbent Spending plus $\$ 5000$ (1978 dollars)

$C E=\log$ of Challenger Spending plus $\$ 5000$ (1978 dollars)

Par $=$ expected vote from district presidential vote plus year effects

$L N V=$ incumbent's Lagged Net Vote (vote minus Par) from the previous election

$T=$ time, in years

As an estimate of the expected vote absent candidate effects, Par allows us to pool data across years. As the deviation from Par in the previous election, the Lagged Net Vote reflects the incumbent's previous vote. The Lagged Net Vote represents the combination of the incumbent's and the challenger's personal vote in the previous election, including that portion due to spending effects. ${ }^{3}$

Time is included in our equations as a control. It is well known that over time, incumbents increasingly spend more in real terms, independent of electoral marginality. To the extent the incumbency advantage has increased, it is important to sort out money versus other sources represented by time as the contributing causes. $^{4}$

\footnotetext{
${ }^{3}$ This model does not imply that candidates observe the vote outcome exactly. Candidates spend in response to their personal expectations of the incumbent vote. These expectations are linear functions of the actual vote but with random error. Below, however, we modify this assumption.

${ }^{4} \mathrm{We}$ do not include the challenger's prior office as a quality proxy in this analysis on the grounds that this variable is endogenous. Inclusion, however, does not affect the results in any significant way.
} 
There are two standard approaches to identifying a system of equations such as this, in order to estimate its structural parameters. This first is to employ exclusion restrictions, in which certain exogenous variables are assumed to enter some of the equations, but are excluded from the other equations (i.e., the coefficients in the equations where they are "excluded" are assumed to be exactly equal to 0 ). The second approach is to impose restrictions on the variance-covariance matrix of the residuals.

Previous work in the context of the vote/spending equations has applied only the exclusion approach, and has done so in the following way. To obtain the necessary identifying exclusion restrictions, a series of assumptions are made in order to identify the coefficients. First, the second equation is assumed not to exist - that is, challenger spending is considered an exogenous variable. In the context of our notation, the assumption is that $\beta_{21}=0$ and $\beta_{22}=0$. Second, identification is finally accomplished by employing an instrument for IE-for instance, lagged values of $I E$. The resulting system of two equations is then estimated by TSLS.

There are several shortcomings of applying this instrumental variables approach to the vote/spending problem, of which we briefly mention two. First, and perhaps most obvious, is that challenger spending is endogenous, for many of the same reasons that incumbent spending is endogenous. The challenger and incumbent are involved in a spending game, and their equilibrium levels of spending are codetermined. To simply throw out one of the equations of a threeequation system is not a reasonable solution. However, this is mainly what has been done because there simply aren't any good instruments for challenger spending. ${ }^{5}$

This lack of a decent instrument for challenger spending brings up the second shortcoming: there aren't very good instruments for incumbent spending either! Thus, what really limits the usefulness of instrumental variables here is the common problem of nonexistence of good instruments for any of the endogenous variables. Finding plausible instruments for the spending variables poses an extremely difficult challenge.

Here is what has been tried in the past. In his TSLS analysis, Jacobson (1978, $1980,1985)$ relied on the presence of a primary challenge as the chief instrument for incumbent spending, and found no appreciable spending effect. Note, however, that Jacobson's null findings rest on the fact that incumbents who survive primary challenges (spending more in the process) show no exceptional success in the general election. This is a shaky foundation, considering that potential primary challengers are more likely to run against incumbents who show signs of electoral weakness.

\footnotetext{
${ }^{5}$ Jacobson (1978) tried a measure of challenger quality (whether the challenger had been elected to prior office) as an instrument for challenger spending. However, this specification ignores the independent effect of challenger quality on the vote.
} 
Green and Krasno (1988, 1990) obtained estimates of stronger incumbent spending effects using a different instrument, namely the lagged value of incumbent spending. The argument is that prior spending only represents the incumbent's "taste" for spending unaffected by current electoral forces, and thus has no direct effect on the current vote. But, as pointed out by Abramowitz (1991) and Jacobson (1990), Green and Krasno's assumptions ignore regression to the mean. Abramowitz's and Jacobson's counterargument can be stated as follows: incumbents spend more in response to strong challenges that lower their vote (in Year $T-2$ ). If the challenge is survived, the incumbent's vote in the next election (Year $T$ ) reverts to normal. Thus, heavy incumbent spending predicts electoral improvement in the subsequent election, or the Green-Krasno finding. Crucially, this is a result that would obtain even if the null hypothesis $\left(\beta_{31}=0\right)$ were true, so long as incumbent spending responds to an effective challenge $\left(\beta_{11}<0\right)$.

In light of the various critiques of these prior estimates, the instruments seem sufficiently dubious to make the estimates of incumbent spending effects highly suspect. Yet, we know that the null findings of OLS estimates are certainly worthless due to simultaneity bias. If so, statistically we know nothing about the true effects of incumbent spending. The result would appear to be a statistical impasse, were there no alternative route to identification. ${ }^{6}$

This leaves covariance restrictions as the natural direction to turn, and here is where the uncorrelated errors assumption provides the needed leverage. ${ }^{7}$ Applied to our problem, the maintained hypothesis is that the disturbance terms for the incumbent spending equation and the challenger spending equation are each uncorrelated with the disturbance term for the vote share equation-in other words, that there are no unmeasured sources of spurious correlation between either $I E$ or $C E$ spending and the vote. The fact that spending is a function of the anticipated or expected vote is turned from a research handicap to a source of analytical leverage. While every variable that affects the vote is a likely cause of spending levels, the effect on spending presumably is indirect via the vote.

\footnotetext{
${ }^{6}$ Indicative of the need for a fresh approach, others have been reexamining the statistical evidence in a variety of ways. Kenny and McBurnette (1994) apply a unique multiequation approach involving survey responses (although ignoring simultaneity). Goidel and Gross (1994) apply three-stage least squares to a model similar to Green and Krasno's. Both papers claim evidence of a significant and appreciable incumbency effect. In another paper, Levitt (1994) controls for candidate effects by analyzing, via OLS, pairs of elections where the same two candidates compete. He estimates spending effects an order of magnitude lower than previous studies, with insignificant incumbent spending effects.

${ }^{7}$ The solution of identification via zero covariance among disturbance terms of endogenous variables is discussed in advanced treatments of the identification problem (e.g., Fisher 1966, chaps. 3-4; Rothenberg 1973, chaps. 4-5; Goldberger 1991, 361-62; Johnston 1963, 248-49; Maddala 1977, 226-28; Malinvaud 1966, 528-38; see also Heise 1975, 181-82; Hanushek and Jackson 1977, 271-76.) For a general discussion, see Hausman and Taylor (1983) and Hausman, Newey, and Taylor (1987). For a political science application, see Erikson 1982.
} 
Meanwhile, unmeasured variables that might affect spending directly are not likely to affect the vote directly.

The basic idea for why this provides the necessary identification is simple in its intuition. Because the residual vote is assumed to be uncorrelated with the spending disturbances, the (standardized) correlation or (unstandardized) covariances between the spending variables and the vote are assumed to be a function only of the two reciprocal effects of spending on votes and votes on spending. Simplifying slightly, the covariance between each spending variable and the incumbent vote is, roughly, the sum of the two effects: of votes on spending and of spending on votes. Since the effects of the incumbent vote on the two spending variables are readily estimated via TSLS, the effects of spending on the vote are estimated (approximately) by subtracting the vote-on-spending coefficients from their respective covariances. If incumbent spending positively affects votes, for example, then the covariance between incumbent spending and the incumbent vote should be more positive than the estimated coefficient for the effect of the incumbent vote on incumbent spending. A positive residual would represent a positive spending effect.

Note that the uncorrelated errors assumption applies to the covariances between the vote and each spending variable, but not between the two spending variables. The model is identified even though it is totally agnostic regarding the reasons why incumbent spending and challenger spending correlate. District demographics and the nature of the local media market(s), for example, can affect both spending variables. Spending by one candidate may affect the spending level of the opponent, apart from an indirect effect via the expected vote. Our model allows for this, if we assume some of the vote-on-spending effect is indirect via opponent spending. For instance, a tight race may cause the challenger to spend, which directly causes the incumbent to spend. If we specify any arbitrary nonzero effects of $I E$ and $C E$ on each other a priori, the direct effects of the vote on spending are affected accordingly. But the estimated effects of the spending variables on the vote remain unaffected by the choice of specification of assumed crossspending effects. All that is required to drive the model is that the sources of the spending-vote correlations are a combination of indirect and direct vote-onspending effects plus (presumably direct) spending-on-vote effects.

\section{Estimated Spending Effects}

Table 2 presents our estimates of the vote equation, including spending effects, while Table 3 presents the companion spending equations. ${ }^{8}$ The system of

\footnotetext{
${ }^{8}$ The data span two decades of congressional elections in the period $1972-90$. We include only cases where the current incumbent had been a candidate in the previous election and faced majorparty opposition - that is, we exclude all elections following bielections and all elections where the incumbent had been unopposed the election before. With still other elections excluded because of redistricting or special circumstances, we have 1,945 veteran cases and 424 freshman cases.
} 
TABLE 2

Estimated Effects of Campaign Spending, 1974-1990: Comparison of Models

\begin{tabular}{lcccccc}
\hline & \multicolumn{2}{c}{ Veteran } & \multicolumn{2}{c}{ House Members } & \multicolumn{2}{c}{ Freshmen House Members } \\
\cline { 2 - 7 } & \multicolumn{2}{c}{ OLS } & \multicolumn{2}{c}{ Uncorrelated Errors } & OLS & \multicolumn{2}{c}{ Uncorrelated Errors } \\
& $\lambda=0$ & $\lambda=1$ & $\lambda_{I}=.39$ & $\lambda=0$ & $\lambda=1$ & $\lambda_{I}=.39$ \\
& & & $\lambda_{C}=.28$ & & & $\lambda_{C}=.28$ \\
\cline { 2 - 8 } & 0.20 & 3.32 & 1.57 & 1.16 & 10.58 & 4.52 \\
Incumbent & $(0.86)$ & $(7.77)$ & $(2.12)$ & $(1.65)$ & $(5.00)$ & $(2.64)$ \\
spending & -3.68 & -0.45 & -2.97 & -4.71 & -0.07 & -3.99 \\
Challenger & $(-28.50)$ & $(-1.71)$ & $(-7.25)$ & $(-15.90)$ & $(-0.08)$ & $(-5.32)$ \\
spending & 0.64 & 1.05 & 0.75 & 0.50 & 1.36 & 0.68 \\
Par & $(27.76)$ & $(27.08)$ & $(15.58)$ & $(8.31)$ & $(8.39)$ & $(6.99)$ \\
& - & - & 0.76 & - & - & 0.75 \\
Short-term & - & - & $(12.06)$ & - & - & $(5.75)$ \\
forces & 0.35 & 0.64 & 0.45 & 0.24 & 0.86 & 0.41 \\
Lagged net vote & $(18.23)$ & $(22.61)$ & $(14.54)$ & $(4.49)$ & $(7.18)$ & $(6.41)$ \\
& 0.01 & -0.22 & -0.10 & 0.03 & -0.71 & 0.22 \\
Time & $(0.26)$ & $(-4.79)$ & $(-1.56)$ & $(0.40)$ & $(-3.86)$ & $(1.50)$ \\
& 5.67 & 7.35 & 5.83 & 5.93 & 10.14 & 6.25 \\
Standard error of est. & .67 & - & - & .64 & - & - \\
Adjusted $R^{2}$ & $(1945)$ & $(1945)$ & $(1945)$ & $(432)$ & $(432)$ & $(432)$ \\
$\quad$ Number of cases & & & & & & \\
\hline
\end{tabular}

Note: Spending $=\log ($ Total expenditures $+5,000)$, all in constant $(1978)$ dollars.

$t$-values in parentheses

In the third and sixth columns, Par excludes short-term forces, and the estimated coefficients and standard errors are obtained without constraining $\lambda$ at a fixed predetermined value. The estimates in the other columns are obtained by constraining $\lambda$ to equal either 0 or 1 .

TABLE 3

Spending Equations, "Uncorrelated Errors" Estimates

\begin{tabular}{|c|c|c|c|c|}
\hline & \multicolumn{2}{|c|}{ Veteran House Members } & \multicolumn{2}{|c|}{ Freshmen House Members } \\
\hline & $\begin{array}{l}\text { Log Incumbent } \\
\text { Spending } \\
(+\$ 5,000)\end{array}$ & $\begin{array}{c}\text { Log Challenger } \\
\text { Spending } \\
(+\$ 5,000)\end{array}$ & $\begin{array}{l}\text { Log Incumbent } \\
\text { Spending } \\
(+\$ 5,000)\end{array}$ & $\begin{array}{c}\text { Log Challenger } \\
\text { Spending } \\
(+\$ 5,000)\end{array}$ \\
\hline Incumbent vote margin & $\begin{array}{c}-0.04 \\
(-21.61)\end{array}$ & $\begin{array}{c}-0.10 \\
(-33.78)\end{array}$ & $\begin{array}{c}-0.05 \\
(-11.94)\end{array}$ & $\begin{array}{c}-0.12 \\
(-17.48)\end{array}$ \\
\hline Time & $\begin{array}{c}0.08 \\
(28.54)\end{array}$ & $\begin{array}{c}-0.00 \\
(-0.35)\end{array}$ & $\begin{array}{c}0.08 \\
(14.89)\end{array}$ & $\begin{array}{c}-0.02 \\
(2.00)\end{array}$ \\
\hline Standard error of est. & .384 & .812 & .510 & .874 \\
\hline
\end{tabular}

Note $:$ Log of Spending $=$ Natural Log of Candidate Spending $+\$ 5,000$, in constant $(1978)$ dollars . $t$-values in parentheses 
equations is estimated separately for veteran and for freshman incumbents. For comparative purposes, the first and fourth columns of Table 2 present the erroneous OLS estimates of the vote equations. As in past studies, we find asymmetrical "effects" with highly "significant" coefficients for challenger spending but virtually no effect for incumbent spending. Even for the newly arrived freshmen, enjoying their sophomore surge, the OLS equations imply that only challenger money matters. It is by now widely accepted that this is not the correct result.

The second and fifth columns show our new uncorrelated errors estimates. ${ }^{9}$ Here we have the reversal of the OLS results. For veteran incumbent races, incumbent spending affects the vote with a statistically significant coefficient of 3.3 ; challenger spending affects the vote only weakly with a statistically insignificant coefficient of -0.5 . For freshman races, the results are even more asymmetrical, with a coefficient in double digits for incumbents but virtually zero for challengers.

Meanwhile, from Table 3 we see that the (anticipated) vote has a powerful influence on spending by incumbents (whether veterans or freshmen) and especially by challengers. The substantively important effects of spending on the vote are almost drowned by the stronger flow from anticipated vote to spending. This would account for the disparity between the uncorrelated errors and OLS findings as do a massive pair of vote-on-spending effects. But this leaves us with a new puzzle to explain, namely that the above specification of the simultaneous equations model somehow "overadjusts" for the simultaneity between spending and the vote, so that now it appears as if challenger spending has only a very small effect.

This apparent puzzle has a simple resolution. Recall that the motivation for the spending equations is that candidates' spending decisions respond to the anticipated vote-i.e., their expectations about how close the election will be. In elections where both candidates expect the incumbent is likely to be in trouble (i.e., incumbent vote is expected to be low), both candidates spend more. In the simultaneous equations estimates, the "anticipated" vote in the spending equation, to which candidates are assumed to respond, is the signal of the actual vote, perceived with error. In contrast, the OLS model generates spending coefficients with the assumption that the signal for the candidates' anticipated vote is limited to the variable in our vote equation. That is, it ignores the fact that the candidates themselves may have some additional information about the specific features of the election in which they are involved that are not captured in our model. Thus, these two estimates represent two extreme assumptions about the correct way to measure the candidates' anticipated vote-one (OLS) in which the candidates know no more about the specific election they are involved in than what is captured in our own simple linear vote equation, and the other in which expectations

\footnotetext{
${ }^{9}$ We obtain maximum likelihood estimates using the statistical software EQS. The third and sixth columns are explained later in the paper.
} 
are further conditioned on the residual error of the vote equation. Clearly the truth lies somewhere in between.

This leads us to the next step of our analysis, which is to estimate the extent to which candidates' expectations of the vote are conditioned on intangible (i.e., unmeasured) sources of the vote that end up as residual error in our vote equation. To do this, we expand the model, by introducing a parameter, $\lambda$, that measures how much spending responds to national short-term forces and to the unobserved residual of the vote equation. In other words, when the vote shifts in a particular year due either to the local campaign-specific factors or to national short-term forces, candidates sense the change equally well (but imperfectly) whichever the source, and spending responds accordingly. The parameter measures the degree of imperfection of these perceptions.

Formally, we estimate $\left(\alpha \beta, \lambda_{I}, \lambda_{C}\right)$ in the following system of three equations. Again we use the restriction that $\operatorname{cov}\left(\epsilon_{1}, \epsilon_{3}\right)=0$ and $\operatorname{cov}\left(\epsilon_{2}, \epsilon_{3}\right)=0$ to identify the system.

$$
\begin{aligned}
& I E=\alpha_{1}+\beta_{11}\left(I V_{\text {obs. }}+\lambda_{I} I V_{\text {unobs. }}\right)+\beta_{12} T+\epsilon_{1} \\
& C E=\alpha_{2}+\beta_{21}\left(I V_{\text {obs. }}+\lambda_{C} I V_{\text {unobs. }}\right)+\beta_{22} T+\epsilon_{2} \\
& I V=\alpha_{3}+\beta_{31} I E+\beta_{32} C E+\beta_{33} N V+\beta_{34} S T F+\beta_{35} L N V+\beta_{36} T+\epsilon_{3} \\
& \quad=I V_{\text {obs. }}+I V_{\text {unobs }}
\end{aligned}
$$

where

$I V_{\text {obs. }}$ (Directly observed sources of incumbent vote $)=I V-I V_{\text {unobs. }}$

$I V_{\text {unobs. }}$ (Indirectly observed or intangible sources of incumbent vote)

$$
=\beta_{34} S T F+\epsilon_{3}
$$

$S T F=$ National Short-Term Forces (year effects)

$N V($ Normal Vote $)=$ Par $-S T F$

Effectively, what we have done is decompose Par into its two components, $N V$ and STF. The $N V$ component of Par, together with $L N V$, reflects variables that are directly observable to the candidates: the pattern of district presidential voting, the vote in the previous election, and the prior election's short-term forces. These enter into the spending equations as before. Short-term forces and the residual of the vote equation are different. While observed ex post facto by the analyst, they are not directly observable by candidates at the time and so their effect on spending must be discounted to reflect this. At the extremes, fully discounting the unobservables would be equivalent to a model with $\lambda=0$ (which is the implicit assumption in the OLS estimates), and perfect parity would correspond to $\lambda=1$ (which is the implicit assumption in the uncorrelated errors estimates above).

This specification permits separate estimation of $\lambda$ for incumbents and challengers, which makes sense since a priori one would expect an incumbent to be better equipped to perceive these effects than the typical challenger. Also, by 
pooling the veteran and freshman systems of equations (while allowing all other coefficients to vary across the two groups) we can obtain one common set of $\lambda$ estimates for freshmen and veterans. These estimates are $\lambda_{I}=.395$ (standard error $=.160$ ) for incumbents and $\lambda_{C}=.278$ (standard error $=.100$ ) for challengers. Thus, judged by the relative responsiveness to short-term forces versus the measurable fundamentals, both incumbent and challenger spending respond to long-term fundamentals considerably more strongly than to the short-term intangibles, with incumbents responding marginally more to the latter than their challenger opponents.

With $\lambda$ estimated in this manner, the freshman vote equation is:

$$
\hat{I V}=\begin{array}{ccccc}
4.52(I E) & -3.99(C E)+0.68(N V)+0.75(S T F)+0.41(L N V)+0.22(T) \\
(2.64) & (-5.32) & (6.99) & (5.75)
\end{array}
$$

The incumbent spending coefficient remains significant and greater than the coefficient for challenger spending. For veteran races, incumbent spending now has a coefficient about half that for challengers:

$$
\begin{aligned}
& \hat{I V}=1.57(I E)-2.97(C E)+0.75(N V)+0.76(S T F)+0.45(L N V)-0.10(T) \\
& \begin{array}{llllll}
(2.12) & (-7.25) & (+15.58) & (+12.06) & (+14.54) & (-1.56)
\end{array}
\end{aligned}
$$

The results above are displayed as the third and sixth columns of Table 2, above. The comparisons with both the OLS (restricting $\lambda=0$ ) and the uncorrelated errors estimates (restricting $\lambda=1$ ) are striking. Although the spending coefficient for veteran incumbents appears only modestly significant, the larger standard error is a function of allowing $\lambda_{I}$ and $\lambda_{C}$ to be free parameters. When $\lambda_{I}$ and $\lambda_{C}$ are constrained to their estimated .395 and .278 values, incumbent spending is highly significant ( $t$-value $=6.19$ ), as it is for any reasonable values of $\lambda_{I}$ and $\lambda_{C}$.

We briefly summarize the findings of this section. The section began by showing that, without a way to identify $\lambda$ in our model, it would be very difficult to pin down the relative effects of incumbent and challenger spending on the vote. At one extreme $(\lambda=0)$, there is no simultaneity problem (candidate expectations of the vote reflect the predicted vote, plus error) and one gets the OLS result that incumbent spending has no effect and challenger spending is very effective. At the other extreme $(\lambda=1)$, the simultaneity problem is full-blown (candidate expectations reflect the actual vote, plus error) and one gets the initial uncorrelated result that is exactly opposite. We estimate $\lambda$ to be roughly one-third (.395 for incumbents, .278 for challengers), yielding a plausible result where both spending effects are important. Breaking this down further provides additional insights. In particular, incumbent spending appears to matter just as much if not more than challenger spending in the crucial freshman election. But the spending of incumbents who have achieved veteran status appears to run into diminishing marginal returns, 
becoming less effective than challengers' spending, just as many congressional scholars have conjectured. ${ }^{10}$

Our next task is a finer-grade analysis of spending effects over the course of the congressional career. In the next section, we document in detail a clear pattern of diminishing marginal returns from spending over the career. And we are able to closely link the accumulation of spending effects over the career to wellknown findings about the time profile of incumbency advantage.

\section{Spending Effects and Incumbency}

In this section, we return to the question posed at the outset: to what extent does incumbent spending account for the incumbency advantage? Clearly, the net spending advantage in the crucial freshman race favors the incumbent over the challenger. Not only do freshmen candidates outspend their challenger, but freshmen spend their money at least as effectively as their opponents. Net spending effects are also relevant, however, beyond the freshman election. We have presented evidence that while incumbent spending definitely appears to matter beyond the freshman election, veteran incumbents spend less effectively than challengers. We intend to relate this fact to the pattern of vote change over the congressional career. Just as the net spending advantage in the freshman election can contribute to the sophomore surge, the net spending advantage (incumbent versus challenger) should contribute to vote shifts later in the career.

The simplest way to estimate the incumbency advantage as a function of seniority is from the "sophomore surge" or the average (party swing-adjusted) vote gain between the first successful election as a nonincumbent (challenger or open seat winner) and the second election, in which the incumbent seeks a second term. Adjusted for partisan swings by means of Par (Net Vote minus Lagged Net Vote), the average sophomore surge in the 1970s and 1980s was 6.4 percentage points. Less well known are the patterns of expected vote gains after the freshman election. Table 4 presents the mean Par-adjusted vote gain (i.e., mean change in the Net Vote) by terms served. Following the second term, the vote gain is positive, as if there were a modest "junior jump" after the more familiar sophomore surge. Following the third term, the net gain is virtually zero--"senior slump." Then, for all subsequent terms, the mean net vote change is negative, averaging a loss of more than 1.0 percentage points per election. Thus, for all intents and purposes, incumbents gain their advantage quickly, mainly in the sophomore year. Thereafter, their vote appeal is almost stationary, and in about the fourth term starts a slow decline.

\footnotetext{
${ }^{10}$ Diminishing marginal returns works for challengers as well. We reestimated spending effects for veteran races using our $\lambda$ estimates, this time separately for repeat challengers $(N=259)$ and for new challengers $(N=1,686)$. Coefficients for repeat and new challengers were -0.59 and -3.15 , respectively. Coefficients for their incumbent opponents were a similar 1.52 and 1.30 . We thank Steven Levitt for his data on repeat challengers.
} 
TABLE 4

Incumbent Vote Gain by Term of Office

\begin{tabular}{|c|c|c|c|c|c|c|c|}
\hline \multirow[b]{3}{*}{ Term } & \multirow[b]{3}{*}{$N$} & \multicolumn{6}{|c|}{ Net Vote } \\
\hline & & \multicolumn{3}{|c|}{ Mean } & \multicolumn{3}{|c|}{ Standard Deviation } \\
\hline & & $\begin{array}{c}\text { Year } \\
T-2\end{array}$ & $\begin{array}{c}\text { Year } \\
T\end{array}$ & $\Delta$ & $\begin{array}{c}\text { Year } \\
T-2\end{array}$ & $\begin{array}{c}\text { Year } \\
T\end{array}$ & $\Delta$ \\
\hline 1 & 432 & 4.3 & 10.9 & 6.6 & 5.9 & 8.3 & 2.4 \\
\hline 2 & 386 & 11.5 & 13.0 & 1.5 & 7.6 & 8.2 & 0.6 \\
\hline 3 & 319 & 13.4 & 13.5 & 0.1 & 7.1 & 8.0 & 0.9 \\
\hline 4 & 253 & 14.1 & 13.0 & -1.1 & 7.1 & 8.2 & 1.1 \\
\hline 5 & 202 & 14.2 & 12.4 & -1.8 & 7.8 & 7.7 & -0.1 \\
\hline 6 & 174 & 13.8 & 12.1 & -1.8 & 7.2 & 8.4 & 1.2 \\
\hline 7 & 146 & 13.8 & 13.3 & -0.5 & 6.8 & 7.6 & 1.8 \\
\hline 8 & 115 & 14.0 & 12.4 & -1.6 & 6.9 & 7.3 & 0.4 \\
\hline 9 & 80 & 13.6 & 11.7 & -1.9 & 7.4 & 8.3 & 1.1 \\
\hline 10 & 59 & 13.1 & 11.2 & -1.9 & 7.2 & 8.1 & 0.9 \\
\hline$>10$ & 211 & 14.0 & 12.1 & -1.9 & 7.5 & 9.3 & 1.8 \\
\hline
\end{tabular}

To estimate the contribution of spending to both the surge and decline of incumbent electoral success, we estimate spending effects separately for each of the first 10 terms of a congressional career. Table 5 presents the estimates, using the .395 and .278 estimates for $\lambda_{I}$ and $\lambda_{C}$. Challenger spending effects are fairly stable over an incumbent's career cycle, but incumbent spending effects drop off considerably after the freshman election and then continue a slow erosion. Yet, incumbents offset their challengers' advantage in spending effects by continuing to outspend their challengers. Part of this is due to the fact that challenger spending falls off as a function of seniority. Incumbent spending also declines steadily with seniority, but somewhat more slowly. The net spending effect $\left[\beta_{I}(I E)+\right.$ $\beta_{C}(C E)$ ] becomes noticeably negative, however, after about the fifth term, primarily due to the progressively lower efficacy $\left(\beta_{I}\right)$ of incumbent spending.

Clearly the pattern of the net spending advantage over the career mirrors the pattern of vote change over the career. How perfectly or imperfectly spending effects account for the totality of the vote change over the career depends on the assumptions we impose regarding the dynamics of the process. Figure 1 presents the observed change in the Net Vote by term (from Table 4, but with observations for terms 0 and 1 based on open seat winners only). Overlaid with observed change is the accumulation of the net spending advantage, assuming spending effects persist over time without decay. The gap between the two trend lines represents the presumed incumbent advantage from sources other than spending. The close fit between the two curves suggests the intriguing conjecture that net spending might account for all except for roughly four percentage 
TABLE 5

Spending and Estimated Spending Effects, by Number of Terms, Assuming $\lambda_{1}=.395, \lambda_{C}=.282$

\begin{tabular}{|c|c|c|c|c|c|c|c|c|}
\hline \multirow[b]{2}{*}{ Term } & \multirow[b]{2}{*}{$N$} & \multicolumn{3}{|c|}{$\begin{array}{c}\log \\
\text { Incumbent Spending* }\end{array}$} & \multicolumn{3}{|c|}{$\begin{array}{c}\text { Log } \\
\text { Challenger Spending* }\end{array}$} & \multirow{2}{*}{$\begin{array}{c}\begin{array}{c}\text { Estimated } \\
\text { Mean Net } \\
\text { Spending Effect }\end{array} \\
\beta_{I} \overline{I E}+\beta_{C} \overline{C E} \\
\end{array}$} \\
\hline & & $\overline{I E}$ & $\beta_{I}$ & $\left(t_{\beta I}\right)$ & $\overline{C E}$ & $\beta_{C}$ & $\left(t_{\beta c}\right)$ & \\
\hline 0 & $(404)$ & $3.61^{a}$ & $4.70^{b}$ & $(12.80)$ & $3.00^{c}$ & $-4.70^{b}$ & $(-12.80)$ & $2.33^{d}$ \\
\hline 1 & (432) & $3.41^{e}$ & 4.51 & $(5.61)$ & $2.14^{e}$ & -3.99 & $(-12.03)$ & 6.84 \\
\hline 2 & (386) & 3.32 & 2.23 & (3.47) & 2.00 & -3.48 & $(-10.89)$ & 0.06 \\
\hline 3 & (319) & 3.28 & 1.05 & (1.42) & 1.88 & -2.88 & $(-8.56)$ & -2.10 \\
\hline 4 & (253) & 3.31 & 2.33 & (2.64) & 1.90 & -3.26 & $(-7.87)$ & 1.42 \\
\hline 5 & (202) & 3.25 & 1.12 & (1.61) & 1.74 & -2.71 & $(-7.65)$ & -1.27 \\
\hline 6 & (174) & 3.22 & 1.65 & (1.96) & 1.74 & -3.16 & $(-7.07)$ & -0.38 \\
\hline 7 & (146) & 3.21 & 0.46 & $(0.52)$ & 1.65 & -2.15 & $(-4.27)$ & -2.10 \\
\hline 8 & (115) & 3.10 & 0.90 & (1.06) & 1.41 & -3.04 & $(-6.49)$ & -1.69 \\
\hline 9 & (80) & 3.19 & 1.24 & (0.98) & 1.48 & -3.37 & $(-5.52)$ & -1.90 \\
\hline 10 & (59) & 2.97 & 0.63 & $(0.48)$ & 1.32 & -2.04 & $(-2.58)$ & -1.70 \\
\hline
\end{tabular}

${ }^{a}$ Mean spending as first-time winner

${ }^{b}$ OLS estimates, $\beta$ 's constrained to be equal

${ }^{c}$ First-time winners' mean opponent spending

${ }^{d}$ Estimated mean contribution of spending to first-time victory

${ }^{e}$ Open seat winners only

$*$ Log spending $=(\log$ of spending $-\$ 5,000)-\log (\$ 5,000)$

points of the incumbency advantage, and this is nearly constant over the entire career. ${ }^{11}$

\section{Conclusions}

Our results lead to two basic conclusions. The first is that we provide strong evidence on the debate about the effect of current incumbent spending on incumbent vote in the current election year. Our statistical evidence shows very

\footnotetext{
${ }^{11}$ Several directions are possible for a more general treatment of the estimation of the spending components of the incumbency advantage. The most obvious would be to allow some decay in the effect of current spending on future elections. We have assumed that the spending advantage generated by the current election carries over $100 \%$ into future elections. That is, to the extent that differential spending in the current campaign may have affected voters' impressions about the desirability of the incumbent, this effect is permanent rather than transitory. An alternative model would assume a transitory component to the spending effects of the current campaign, since some aspects of the campaign are really specific to the current challenger and will be ignored by voters in future elections. We might also assume that the effects of challenger spending decay more readily than do the effects of incumbent spending, since much of challenger spending is simply geared toward name recognition.
} 
FIGURE 1

Net Vote and Cumulative Spending Effects over Congressional Careers

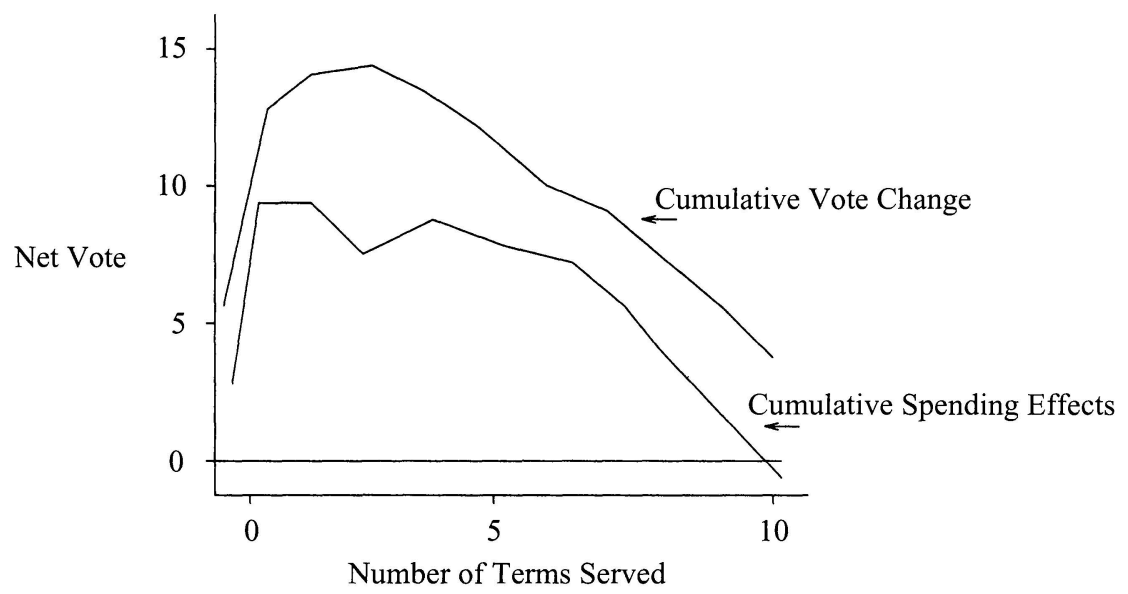

clearly that current incumbent spending matters, and that the effect of this spending varies systematically over the career, beginning as a very strong effect and eventually declining with seniority. A methodological innovation of our analysis is identification of the spending and vote equations by imposing covariance restrictions on the matrix of residuals. This "uncorrelated errors" assumption simply means that the correlations between the spending variables and the vote are the result of variables in the model and not omitted variables.

The second, most important conclusion of this paper goes more deeply to the mechanism by which spending helps incumbents. In particular, we present evidence that incumbent spending has a long-term effect on incumbent success. That is, current spending not only helps an incumbent in the current election, but has a persistence to it, which makes it a major factor contributing to the oftnoted advantage of incumbency in congressional elections. This is a much different view from the standard one, which focuses only on the short-term effects of spending in the current election. Besides being plausible on theoretical grounds, the cumulative effects of spending that we estimate also produce a very close empirical match with the time profile of incumbency advantage, as measured by how well incumbents of different seniorities outperform expectations (our "Par" measure).

Summarizing, incumbent spending is a major contributing factor to the incumbency advantage. We see incumbents' spending advantage as a cumulative process. Among nonincumbent candidates, the strongest are able to spend more, enhancing their chances of victory, so that newly elected house members' reputations are already enhanced by their spending in their first successful race. They 
accumulate a sophomore surge by again outspending their opponents and spending more effectively during their first reelection race. Throughout the career, this spending advantage accumulates with diminishing rates of return. With time, incumbent spending is less effective than challenger spending, but challengers face two special burdens: they generally raise and spend less cash than the incumbents they are trying to unseat, and they must combat the incumbent's positive reputation built in large part by past spending. When the incumbent is electorally weakened, however, challengers enjoy two advantages of their own: weakened, senior incumbents gain little by new spending, and credible challengers can spend competitively.

Manuscript submitted 14 October 1996

Final manuscript received 1 September 1997

\section{References}

Abramowitz, Alan I. 1991. "Incumbency, Campaign Spending, and the Decline of Competition in U.S. House Elections." Journal of Politics 53:34-56.

Alford, John, and David Brady. 1993. "Personal and Partisan Advantages in U.S. Congressional Elections, 1846-1990." In Congress Reconsidered, ed. L. C. Dodd and B. I. Oppenheimer. 5th ed. Washington: Congressional Quarterly Press.

Bartels, Larry. 1992. "Instruments and 'Quasi-Instrumental' Variables." In Political Analysis, Vol. 2, ed. James Stimson. Ann Arbor: University of Michigan Press.

Erikson, Robert S. 1972. "Malapportionment, Gerrymandering, and Party Fortunes in Congressional Elections." American Political Science Review 66:1234-45.

Erikson, Robert S. 1982. "The 'Uncorrelated Errors' Approach to the Problem of Causal Feedback." Journal of Politics 44:863-81.

Erikson, Robert S., and Thomas R. Palfrey. 1993. "The Spending Game: Money, Votes, and Incumbency in Congressional Elections." California Institute of Technology Working Paper No. 851.

Fisher, Franklin M. 1966. The Identification Problem in Econometrics. New York: Academic Press.

Gelman, Andrew, and Gary King. 1990. "Estimating Incumbency Advantge without Bias." American Journal of Political Science 34:1142-64.

Goidel, Robert K., and Donald A. Gross. 1994. "A Systems Approach to Campaign Finance in House Elections." American Politics Quarterly 22:125-51.

Goldberger, Arthur S. 1991. A Course in Econometrics. Cambridge: Harvard University Press.

Green, Donald P., and Jonathan S. Krasno. 1988. "Salvation for the Spendthrift Incumbent: Reestimating the Effects of Campaign Spending in House Elections." American Journal of Political Science 32:884-907.

Green, Donald P., and Jonathan S. Krasno. 1990. "Rebuttal to Jacobson's 'New Evidence for Old Arguments.' "American Journal of Political Science 34:363-72.

Hanushek, Eric A., and John E. Jackson. 1977. Statistical Methods for Social Scientists. New York: Academic Press.

Hausman J. A., W. K. Newey, and W. E. Taylor. 1987. "Efficient Estimation and Identification of Simultaneous Equation Models with Covariance Restrictions." Econometrica 55:849-74.

Hausman, J. A., and W. E. Taylor. 1983. "Identification in Linear Simultaneous Equation Systems with Covariance Restrictions: An Instrumental Variables Interpretation." Econometrica $51: 1527-49$. 
Heise, David B. 1975. Causal Analysis. New York: Wiley.

Jacobson, Gary C. 1978. "The Effects of Campaign Spending in Congressional Elections." American Political Science Review 72:469-91.

Jacobson, Gary C. 1980. Money in Congressional Elections. New Haven: Yale University Press.

Jacobson, Gary C. 1985. "Money and Votes Reconsidered: Congressional Elections, 1972-1982." Public Choice 7:7-62.

Jacobson, Gary C. 1990. "The Effects of Campaign Spending in House Elections: New Evidence for Old Arguments." American Journal of Political Science 34:334-62.

Johnston, J. 1963. Econometric Methods New York: McGraw-Hill.

Kenny, Christopher, and Michael McBurnette. 1994. "An Individual-Level Multiequation Model of Expenditure Effects in Contested Electons." American Political Science Review 88:699-707.

Levitt, Steven D. 1994. "Using Repeat Challengers to Estimate the Effect of Campaign Spending on Election Outcomes in the U.S. House." Journal of Political Economy, Vol. 102:777-98.

Maddala, G. S. 1977. Econometrics. New York: McGraw-Hill.

Malinvaud, E. 1966. Statistical Methods of Econometrics. Chicago: Rand McNally.

Rothenberg, Thomas S. 1973. Efficient Estimation with A Priori Information. New Haven: Yale University Press.

Robert S. Erikson is a Dr. Kenneth L. Fay Professor of Political Science at the University of Houston, Houston TX 77204-3474.

Thomas Palfry is a professor of economics and political science at the California Institute of Technology, in Pasadena, CA 91125. 